\title{
Marijuana smoking among school-aged adolescents in the Brčko District of Bosnia and Herzegovina: A cross-sectional study
}

\author{
Anto Domić ${ }^{1}$, Husref Tahirović ${ }^{2}$, Mojca Čižek Sajko ${ }^{3}$, Borislav Đulabić ${ }^{4}$
}

${ }^{1}$ Government of Brčko District of BIH, Brčko, Bosnia and Herzegovina ${ }^{2}$ Department of Medical Sciences of the Academy of Sciences and Arts of Bosnia and Herzegovina, Sarajevo, Bosnia and Herzegovina, ${ }^{3}$ Institute for Biostatistics and Medical Informatics, Faculty of Medicine, Ljubljana, Slovenia, ${ }^{4} \mathrm{PHI}$ Health Center Brčko, Brčko, Bosnia and Herzegovina

\footnotetext{
Correspondence: anto.domic67@gmail.com

Tel.: + 38765815000

Fax.: + 38749490020
}

Received: 22 March 2017

Accepted: 13 May 2017

Key words: Marijuana smoking Adolescence - Epidemiology.

\begin{abstract}
Objective. The aim was to determine the prevalence of marijuana smoking among school-aged adolescents in the Brčko District of Bosnia and Herzegovina, with particular regard to their gender, age and residence, and the frequency of marijuana smoking in the past thirty days in relation to their peers in the rest of Bosnia and Herzegovina, the Republic of Croatia and the Republic of Serbia. Subjects and methods. This research, designed as a cross-sectional study and based on the ESPAD (European School Survey Project on Alcohol and Other Drugs) questionnaire, adjusted to this research, encompassed 4,188 adolescents from elementary and secondary schools. The data were collected by means of questionnaires tailored to each respondent. Results. A significantly lower number of adolescents smoke marijuana in comparison to those who do not smoke, but male adolescents smoke more often than female adolescents $(\mathrm{p}<0.001)$, as well as urban youth in comparison to rural youth $(p=0.04)$. Every fourth adolescent, regardless of gender, who smoked marijuana, used it before the age of thirteen $(\mathrm{p}<0.001)$, male adolescents more often than females $(p=0.002)$. In the previous thirty days a higher percentage of all the respondents from the Brčko District had smoked marijuana than those from the Republika Srpska and the RS ( $<<0.001)$, and there is no difference between them and their peers from the Federation of Bosnia and Herzegovina and the RC ( $\mathrm{p}=0.382$ and $\mathrm{p}=0.608)$. Conclusion. Smoking marijuana in the Brčko District is a major public health problem. Male adolescents smoke marijuana more often than female adolescents, and urban youth more in comparison to rural youth. In the previous thirty days adolescents from the Brčko District smoked more often than their peers from the Republic of Serbia and the Republika Srpska, and with the same intensity but less frequently compared to adolescents from the Republic of Croatia and the Federation of Bosnia and Herzegovina.
\end{abstract}

\section{Introduction}

Cannabis is the most commonly used illicit narcotic substance in the world (1-4). It is a generic term used to denote several psychoactive substances generated from the plant
Cannabis sativa (5). In accordance with the Single Convention on Narcotic Drugs, 1961, cannabis is defined as "the flowering or fruiting tops of the cannabis plant from which the resin has not been extracted, by whatever name they may be designated" (6). It is 
the dry, greenish-gray mixture of leaves and flowers of cannabis that exists in three main forms: herbal cannabis or marijuana that originates from the dried leaves and flowering tops; cannabis resin - made by compression of the plant and it is known as hashish, and cannabis oil, mixtures that are the result of distillation or extraction of the active plant ingredients $(5,7)$.

Marijuana can be used in different ways such as hand-rolled cigarettes called joints, or many use pipes or marijuana cigars (7, 8). The main psychoactive chemical in marijuana, responsible for most of the psychoactive effects, is delta-9-tetrahydrocannabinol (THC) $(9,10)$. Besides THC, the plant also contains more than 400 other chemicals and more than 60 metabolic compounds chemically related to THC, with no psychoactive effects, called cannabinoids (10).

Smoking marijuana usually starts during adolescence. The beginning of adolescence is linked with the physiological onset of puberty, and ends when the adolescent assumes the identity and behavior of an adult (11). The World Health Organization (WHO) identifies adolescence as the period that occurs from ages 10 to 19 years, and it is roughly divided into three stages: early adolescence, middle adolescence and late adolescence (12). This period is characterized by significant physical, emotional and intellectual changes, with changes in social roles, relationships and expectations (13).

Earlier studies showed that marijuana use among a general population of adolescents was a relatively common occurrence (14), and that marijuana use almost always precedes use of other illicit substances, such as cocaine, methamphetamine, hallucinogens, heroin and morphine (15). Adolescents who smoke marijuana suffer adverse health effects with psychosocial and physical consequences, such as poor family relationships, financial problems, education interruption, delinquent behavior, promiscuity, unplanned pregnancy, sexually transmitted diseases, poor sleep quality, memory loss and attention deficits (16). Marijuana addiction is similar to the addiction caused by other narcotics, and occurs in $14-17 \%$ of adolescents who consume it $(2,8)$. The influence of peers who use marijuana has been identified as one of the important risk factors associated with the onset of cannabis use (17). Several studies have shown that adolescents who use drugs often socialize with friends who also use drugs, and adolescents who do not take drugs are significantly less likely to have friends who use drugs (18-20). If they socialize with friends who use drugs and have a dominant role in society, then this could trigger their more frequent use of drugs (17-20). Perceptions about marijuana use show that it is more frequently smoked by males, who consume it longer and with more intensity, while females are less likely to use marijuana, and the consequences of its use are harmful for females health (21). Nowadays, marijuana can be found everywhere from cities to rural neighborhoods. The studies so far have generally confirmed equal access regardless of the place of residence $(22,23)$. According to WHO, about 147 million people or $2.5 \%$ of the world population consume marijuana, and the prevalence of cannabis use is growing much more quickly compared to other drugs (24).

In many countries the use of marijuana is continuously rising, and it is most commonly used in Western and Central Africa, Western and Central Europe as well as in North America. Europe is still one of the largest markets of marijuana, although the intensity of use varies from country to country. It is most frequently used in Western and Central Europe (25). The frequency of marijuana use is determined by public opinion, which is divided over the control and use of marijuana, and there are more and more people lobbying for liberalized marijuana access. Many countries have created a legal 
basis for decriminalization of marijuana and its use for medical purposes, which affects the frequency of consumption $(10,26)$.

According to the European School Survey Project on Alcohol and Other Drugs (ESPAD) 2011 (25), 16\% of adolescents in the Member States reported having used marijuana at least once in their life, while in the United States (USA) around 35\% of them had done so $(19,25,27,30)$. In the Republic of Croatia (RC) $18 \%$ of respondents reported having used marijuana at least once in their life, while in the Republic of Serbia (RS) only 7\% of respondents had done so. The studies researching the use of marijuana monitor use of marijuana in the previous 30 days, and the ESPAD research demonstrated that $7 \%$ of adolescents in the participating countries had used marijuana in the previous 30 days, while in the USA $18 \%$ of respondents had consumed cannabis in the previous 30 days; in RC $7 \%$ of respondents and $3 \%$ of the respondents in the RS had done so (25).

In Bosnia and Herzegovina (BH) there are no aggregate data for the entire country, but there are data for the Republika Srpska, where $4 \%$ of the respondents had consumed marijuana at least once in their lives, while in the Federation of $\mathrm{BH} 8 \%$ of the respondents had consumed marijuana at least once in their lifetime. One percentage of the respondents from the Republika Srpska and $3 \%$ of the respondents from the Federation of $\mathrm{BH}$ had consumed cannabis in the previous 30 days (25). However, this research did not include the Brčko District, a local unit of self-governance with special status, under the sovereignty of $\mathrm{BH}$, located in the Northeastern part of $\mathrm{BH}$, at the intersection of domestic and international routes linking East and West, and North and South.

The aim of this research was to determine the frequency of marijuana smoking among adolescents in Brčko District public schools, with particular regard to their gen- der, age and residence, as well as in relation to the rest of $\mathrm{BH}, \mathrm{RS}$ and $\mathrm{RC}$.

\section{Subjects and methods}

\section{Area of research}

The Brčko District (Figure 1) covers an area of 493.3 square kilometers. In 2011 it had 75,625 inhabitants with an average population density of 153 inhabitants per square kilometer, which represented a higher population density than some other areas in its vicinity. Of the total population, $24.2 \%$ were children and adolescents. In 2011, a total of 905 children were born in the area of the Brčko District, so the birth rate was $11.9 \%$, while the rate of natural increase was negative and amounted to $0.6 \%$ (27).

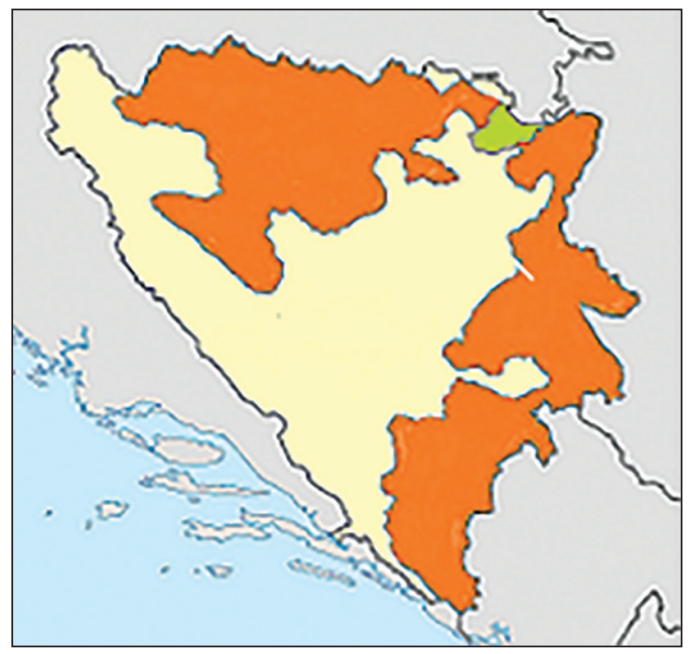

Figure 1 The area of the Brčko District of Bosnia and Herzegovina is colored green, the area of Republika Srpska is colored orange, and the Federation of Bosnia and Herzegovina is colored yellow (28).

\section{Subjects}

According to the plan, all ninth grade elementary school pupils were to be included in the research, plus all secondary school students in the Brčko District, which is 4,676 students in total. Of that number, 1,016 
were ninth grade pupils from 12 elementary schools with subsidiary schools, and 3,660 students were from four high schools. The research encompassed 4,188 or $89.6 \%$ of all the students with average 15.6 years.

\section{Methods}

The research was designed as a cross-sectional study and was conducted by means of an ESPAD questionnaire (25) adapted to this research and translated into the official languages of $\mathrm{BH}$. The questionnaire was created and published by a group of experts from the European Monitoring Centre for Drugs and Drug Addiction (EMCDDA) and the Pompidou Group, which was founded by the Council of Europe in order to enable comparison and analysis of the results of cigarette and narcotics consumption surveys in different countries. The questionnaire contained 45 questions, divided into appropriate thematic units. The questionnaire prepared for this research was used to gather demographics for all adolescents.

After prior approval had been granted by school principals, the research was conducted during the 2011-2012 school year, from 20 October to 28 November 2011, in one school year. The students filled out the questionnaires by themselves, following an explanation given by a person specially trained for completing the questionnaire. The person supervising the test helped the students to fill out the questionnaire, explaining the questions, but did not influence the final answer. After completing the questionnaire, the students put them in envelopes, that were sealed and handed over to the person supervising the process. The adolescents' responses to the following questions were used in this article: "Have you ever smoked marijuana? When was the first time you smoked marijuana? How many times have you smoked marijuana in the past 30 days?" and the frequency of smoking in relation to the Federation of $\mathrm{BH}$, the $\mathrm{RS}$, the $\mathrm{RC}$ and the RS was calculated. Smoking marijuana for the first time was analyzed in relation to the gender, age and place of residence (rural - urban) (29) of the adolescents.

\section{Ethics statement}

The respondents voluntarily agreed to fill out the questionnaires anonymously after being informed that the results would be used for scientific purposes. The questionnaire used in the study was taken from the scientific literature and was quoted in the references.

\section{Statistical analysis}

We presented the prevalence of individual responses to the questions asked in the questionnaire as absolute and relative numbers, and we displayed them in tables or graphs. Binomial or Pearson's chi-square test were applied for analyses of the impact of the students' age, gender and place of residence on the prevalence of marijuana consumption, and to compare that prevalence in the Brčko District with the prevalence in other parts of $\mathrm{BH}$ and neighboring countries. Statistical significance was confirmed at $\mathrm{p}<0.05$. We used the statistical analysis software package SPSS 20 (SPSS Inc., Chicago, Illinois, USA) for data processing.

\section{Results}

Among 4,188 respondents who accessed the research, 4,084 filled out the data about gender, of which 2,013 (49.3\%) were boys and 2,071 (50.7\%) girls. When asked about smoking marijuana 115 (2.8\%) of respondents did not answer and the frequency of marijuana smoking by gender was calculated from a sample of 3,969 respondents, of whom 1,950 (49.1\%) were boys and 2,019 $(50.9 \%)$ were girls. The answer to the ques- 
tion about smoking marijuana as regards the place of residence was not provided by 238 (5.7\%) respondents, so the frequency of marijuana smoking among the students from rural and urban areas was calculated from a sample size of 3,950 respondents of which $54.9 \%(2,169)$ were from rural and $45.1 \%(1,781)$ from urban areas. Table 1 shows cannabis consumption among adolescents in the Brčko District by gender and place of residence.

The results showed that a statistically significant lower number of respondents had smoked marijuana in relation to those who had never smoked it [578 (14.6\%):3391 $(85.4 \%)$; chi-square test, $\mathrm{p}<0.001]$ and that male adolescents statistically significantly more often smoked marijuana in relation to female adolescents [373 (19.1\%):205 $(10.2 \%)$; chi-square test, $\mathrm{p}<0.001]$. When comparing the marijuana smoking results in relation to the place of residence, it was established that a significantly higher number of adolescents from the city had smoked marijuana in relation to those from villages [310 (17.4\%):267 (12.3\%); chi-square test, $\mathrm{p}=0.04]$. The results of the first marijuana smoking according to the age of students living in the Brčko District, by gender and place of residence are displayed in Table 2.

The correlation between age, gender and place of residence of all the respondents who reported that they had smoked marijuana and the first time of smoking mari-

Table 1 Marijuana smoking among school-aged adolescents in the Brčko District, by gender and place of residence

\begin{tabular}{|c|c|c|c|c|}
\hline \multirow{2}{*}{ Gender and place of residence } & & \multicolumn{3}{|c|}{ Marijuana smoking among students of the Brčko District } \\
\hline & & No (n; \%) & Yes $(n ; \%)$ & Total $(n ; \%)$ \\
\hline \multicolumn{5}{|l|}{ Gender } \\
\hline Male & & $1577(80.9)$ & $373(19.1)$ & $1950(100)$ \\
\hline \multirow[t]{2}{*}{ Female } & & $1814(89.8)$ & $205(10.2)$ & $2019(100)$ \\
\hline & Total & 3391 (85.4) & $578(14.6)$ & $3969(100)$ \\
\hline \multicolumn{5}{|l|}{ Place of residence } \\
\hline City & & $1471(82.6)$ & $310(17.4)$ & $1781(100)$ \\
\hline Village & & $1902(87.7)$ & $267(12.3)$ & $2169(100)$ \\
\hline & Total & $3373(85.4)$ & $577(14.6)$ & $3950(100)$ \\
\hline
\end{tabular}

Table 2 The number of students in Brčko District according to age of first marijuana smoking by gender and place of residence

\begin{tabular}{|c|c|c|c|c|c|}
\hline \multirow{2}{*}{$\begin{array}{l}\text { Gender and place of } \\
\text { residence }\end{array}$} & \multicolumn{5}{|c|}{ Age of first marijuana smoking in years ( $n$; \%) } \\
\hline & $\leq 13$ & 14 & 15 & 16 & Total \\
\hline \multicolumn{6}{|l|}{ Gender } \\
\hline Male & $42(23.5)$ & $27(15,1)$ & $47(26.2)$ & $63(35.2)$ & $179(67.8)$ \\
\hline Female & $18(21.2)$ & $11(12.9)$ & $16(18.8)$ & $40(47.1)$ & $85(32.2)$ \\
\hline Total & $60(22.7)$ & $38(14.4)$ & $63(23.9)$ & $103(39)$ & $264(100)$ \\
\hline \multicolumn{6}{|l|}{ Place of residence } \\
\hline City & $29(20.4)$ & $25(17.7)$ & $31(21.8)$ & $57(40.1)$ & $142(53.8)$ \\
\hline Village & $32(26.2)$ & $14(11.5)$ & $31(25.4)$ & $45(36.9)$ & $122(46.2)$ \\
\hline Total & $61(23.1)$ & $39(14.8)$ & $62(23.5)$ & $102(38.6)$ & $264(100)$ \\
\hline
\end{tabular}


juana was studied. The results we obtained showed that there was a difference between male and female adolescents when they first smoked cigarettes regarding their age [179 (67.8\%): 85 (32.2\%); Chi-square test, $\mathrm{p}<0.001]$. Nearly a quarter of adolescents, regardless of gender, who reported that they had smoked marijuana, had done so before the age of thirteen [(60/264); chi-square test, $\mathrm{p}<0.001$ ], while males smoked marijuana at that age more often compared to their female peers [ $42(23.5 \%): 18$ (21.2\%): chisquare test, $\mathrm{p}=0.002]$. Female adolescents more often began smoking marijuana at the age of $16(47.1 \%)$ compared to male adolescents $(35.2 \%)$. When it comes to the place of residence, the results showed that more than half of the respondents who had smoked marijuana lived in the city [142 (53.8\%): 122 (46.2\%); Chi-square test, $\mathrm{p}<0.001]$. Every fourth respondent who had tried marijuana before the age of thirteen lived in the rural area but every fifth respondent who lived in the city [(32:29); Chi-square test, $\mathrm{p}<0.001]$ had done so; the respondents from the city smoked marijuana more often only after the age of $14(\mathrm{p}<0.001)$.

Of all the 578 respondents who answered "yes" to the question about smoking marijuana at all in their life, $41 \%$ of them (237:578) had smoked it 1-2 times. A minimum number of adolescents (5.5\%) had smoked it 20 to 39 times, and $17 \%$ of adolescents more than 40 times.Respondents living in the villages had more often smoked 1-9 times in their lifetime compared to those from the city, who had smoked it between 10 and more than 40 times.

When asked about marijuana smoking in the previous 30 days, $6.6 \%(256 / 3878)$ adolescents from the Brčko District answered "yes". According to the ESPAD research from 2011, 1\% (31/3132) from the Republika Srpska, 6.1\% (181/2966) from the Federation of $\mathrm{BH}, 7 \%$ (210/3002) from the RC and 3\% (182/6084) from the RS gave the same answer. In the Brčko District, the respondents had used marijuana in a significantly higher percentage in the previous 30 days than the students from the Republika Srpska $(\mathrm{p}<0.001)$ and the RS $(\mathrm{p}<0.001)$. The differences between the Brčko District and the Federation of $\mathrm{BH}$, and the $\mathrm{RC}$ were not statistically significant $(\mathrm{p}=0.382$ and $\mathrm{p}=0.608$ ).

Out of 256 respondents who had smoked in the previous 30 days, 115 respondents or $44.9 \%$, had smoked one to two joints, 51 or

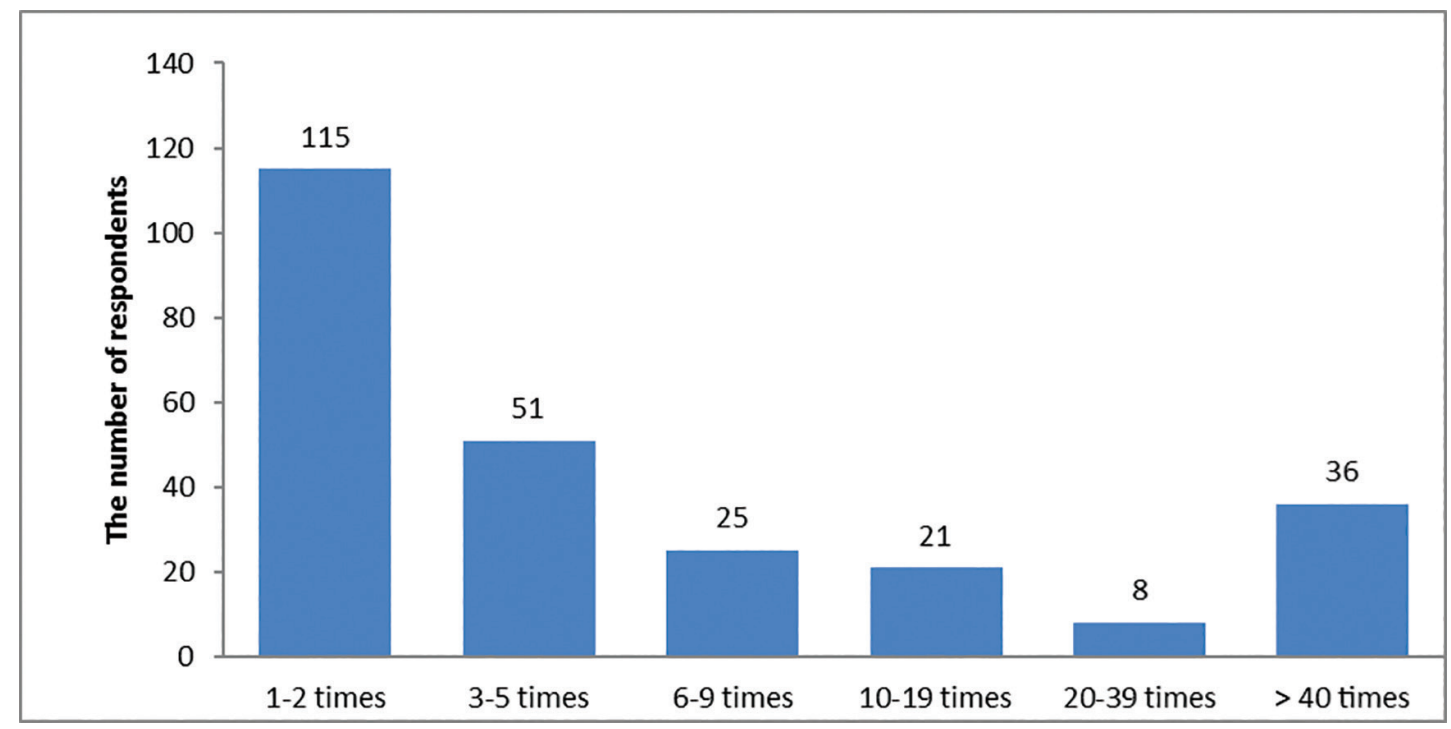

Figure 2 The number of marijuana cigarettes that respondents had smoked on average in the previous 30 days. 
$19.9 \%$ of the respondents had smoked 3-5 joints, 25 respondents or 9.8\% 6-9 joints, 21 adolescents or $8.2 \% 10-19$ joints, 8 respondents or $3.1 \% 20-39$ times, and 36 or $14.1 \%$ of adolescents had smoked it more than 40 times in the previous month (Figure 2).

\section{Discussion}

This research demonstrated that almost one in seven adolescents in the Brčko District (14.6\%) had smoked at least one joint of marijuana in their lifetime, which confirms the high availability and usage of marijuana. Such a high percentage of respondents who had tried to smoke marijuana at least once in their life is distressing because these are young people in early adolescence, when marijuana smoking leads to addiction, causing long term health problems (30). Comparing the data about marijuana smoking from this research with the data about their peers in other parts of $\mathrm{BH}$ (Federation of $\mathrm{BH}$ and Republika Srpska), and in the RC and the RS, we found that adolescents from the Brčko District smoked marijuana less frequently than their peers in the $\mathrm{RC}$, while in relation to their peers from the RS, the Federation of BH and the Republika Srpska they did so much more frequently $(25,31)$. In fact, in the Republika Srpska barely every twenty-fifth (4\%) adolescent had tried to smoke marijuana, while in the Federation of $\mathrm{BH}$ and the RS almost every twelfth (8\%) adolescent had done so (25). Based on the research carried out by other authors, we learned that more than a third (35\%) of adolescents in the USA had smoked marijuana at least once in their lives (19), while in Europe, on average, one in six (16\%) adolescents had tried it (25). It is evident that when it comes to the prevalence of marijuana smoking, adolescents from the Brčko District are more similar to their peers from Europe and the USA than to their peers from other parts of $\mathrm{BH}, \mathrm{RC}$ and the $\mathrm{RS}$ (19, $25,26)$. It is therefore necessary to clarify the reasons why the behavior of adolescents from the Brčko District resembles more the behavior of their peers from distant countries than the behavior of their peers from the region with whom they have frequent contact, share the same geographical area and have similar habits.

When it comes to the relationship between marijuana smoking and gender, we have shown that nearly one in five male adolescents and one in ten female adolescents have tried to use marijuana at least once in their life, which is in line with the results of global research showing that male adolescents smoke marijuana much more frequently than female adolescents $(17,25,31)$. In the Federation of $\mathrm{BH}, 12 \%$ of male adolescents and $4 \%$ of female adolescents had smoked marijuana, while in the Republika Srpska $6 \%$ of male and 3\% of female adolescents had done so. As for the RC and the RS, the neighboring countries, research shows that male adolescents try to smoke marijuana more often compared to female adolescents. So, in the RC, $21 \%$ of male adolescents and $14 \%$ of female adolescents had smoked marijuana, while in the RS $9 \%$ of male and $4 \%$ of female adolescents had smoked marijuana $(19,25)$. Research carried out in the USA showed that $38 \%$ of male adolescents and $31 \%$ of female adolescents had smoked marijuana at least once in their lifetime (19, 25 ), while in Europe on average 19\% of male and $14 \%$ of female adolescents had smoked it (25). The figures illustrate the same trends, i.e. male adolescents smoke marijuana more often than female adolescents, but with different intensity in different countries. Research carried out in the USA and in Europe in the past several years showed that the difference in drug use between men and women is decreasing and it is expected that in the near future males and females will be equally as likely to use drugs $(21,30)$. 
This research has proven to us that boys in the Brčko District are twice as likely to try smoking marijuana than girls. One of the reasons for such behavior may be found in studies that show that women are more prone to taking sedatives and narcoanalgetics, while men are more prone to taking other narcotics, including marijuana $(21,29$, 32 ). Based on this research, we are unable to draw a conclusion about the tendency toward marijuana smoking among male and female adolescents in the Brčko District, because this phenomenon was not the focus of research. It would be necessary to test this claim in future in order to confirm or refute research results that speak of male and female adolescents' preference for marijuana smoking. There are studies that describe the medicinal properties of marijuana that can be used for treatment of certain diseases, and that say that there is justification for the legalization of cannabis, but ultimately all studies come to one conclusion - cannabis has a harmful effect on health (26). Due to the claims that marijuana has medicinal properties, and owing to the fact that it is supposedly less addictive than other narcotics, the tolerance threshold in adolescents for engaging in experimentation with marijuana is being lowered (16). The disturbing fact is that every fifteenth adolescent in the Brčko District had smoked marijuana in the previous 30 days (25), which is almost equal to the number of adolescents from the EU, $\mathrm{RC}$ and Federation of $\mathrm{BH}$, while twice as many respondents from the Brčko District had smoked it in the previous thirty days compared to the RS, and six times more compared to their peers in the Republika Srpska. Active drug addicts were taken to be adolescents who had smoked marijuana in the previous thirty days. Half of them had smoked one to two joints, while one in four had smoked up to five joints of marijuana. One in seven respondents, who said they had used marijuana in the past month, had smoked a minimum of one joint per day on average. This intensity of marijuana smoking suggests that it has become an integral part of the everyday activities of adolescents, and that marijuana smoking is a matter of prestige and is not perceived as a vice or something they should avoid.

From the analysis of when the respondents use marijuana, we established that more than one fifth of school-aged adolescents who had ever smoked it, had done so before the age of thirteen. This number represents $1.5 \%$ of the respondents and is significantly higher than in the rest of $\mathrm{BH}$ and the RS, where $1 \%$ of the respondents had tried marijuana before the age of thirteen, while in RC $3 \%$ of them had, which represents the average of the members of the ESPAD group (25). In the USA, this percentage rises to $15 \%$ (26). Bearing in mind that we are talking about early adolescence, it is difficult to understand that such a large number of respondents had had the opportunity to obtain marijuana so early in their life and decided to smoke it.

One of the elements which could be seen as a reason for the existence of these drastic differences is the location of the District, which is topographically "nested" between the Republika Srpska and the Federation of $\mathrm{BH}$. Also, it is situated on the border with the EU and it is autonomous in terms of other levels of government. Consequently, migration to and from the Brčko District is extensive. This location and its autonomy make it safe for dealers to trade in marijuana and place their "goods" not only on the market in the Brčko District and $\mathrm{BH}$, but also on the markets of EU countries.

This research shows that respondents from the city are prone to use marijuana more often than those from villages. It shows that one in six respondents from the city had smoked marijuana, and that one in eight respondents from villages had done so. If any difference exists in relation to the place of 
residence and marijuana consumption, it has decreased and it is only a matter of time until the place of residence will be irrelevant with regard to marijuana consumption. This observation is supported by the fact that 13 year old respondents from the villages use marijuana much more frequently than their peers from the city. The claim that marijuana is finding its way to rural areas is thus affirmed. The higher intensity of marijuana smoking in rural areas could be the result of the imprecise definition of the term "village", since there are more and more rural areas which in certain circumstances are considered to be urban areas $(22,23,33)$. The difference in marijuana consumption could be explained by the fact that rural people are more conservative, less educated, stricter in raising their children, and poorer in comparison to those from the city.

The influence of peers and identification with their idols who tend to use marijuana may be the trigger for adolescents to try to smoke marijuana (18). Social networking sites such as Facebook, Twitter, etc., and socializing with virtual friends and their peers who already use marijuana create more fertile ground for adolescents to engage in an "adventure" and to purchase and consume marijuana (34). Likewise, through social networks and other media, adolescents very quickly obtain information about the trends in medical usage of marijuana and the process of its legalization in some countries of the world, which can create a distorted picture of the ingenuousness of narcotic substances (26). The search for the best way to combat this scourge is aggravated by all this. Research conducted in the USA shows that unstable families have a significant impact on the behavior of adolescents, especially single-parent households (33). In such families, adolescents are much more likely to behave in a risky manner, and they consume drugs more often in comparison to those from two-parent families (35). In families where the parents have built better family relations with their children and where the parents exercise subtle control of the adolescents' actions, risky behavior and consumption of narcotics rarely appear (36). This problem was not the subject of this research, and it is necessary to design new research in order to research this phenomenon scientifically and to draw adequate conclusions.

\section{Limitation of study}

A weakness related to the research problem is the inability to check whether the respondents answered the questions truthfully. The research involved adolescents prone to turbulent emotional and social reactions that may affect their giving honest answers. One of the limiting factors was the insufficient involvement of school psychologists and teachers, who could have contributed to making respondents answer truthfully.

\section{Conclusion}

Every seventh respondent had tried smoking marijuana at least once in their lifetime, and every fifteenth respondent had smoked marijuana in the previous thirty days. Boys smoke marijuana much more frequently than girls, as do city boys compared to those from villages. Adolescents from the Brčko District had smoked marijuana in the previous thirty days more often than their peers from the RS and the Republika Srpska, and as much as their peers in the RC and the Federation of $\mathrm{BH}$. On the whole, marijuana is easily available in the Brčko District, and its consumption is tolerated, which is an important public health problem.

\section{What is already known on this topic}

Marijuana is the most commonly used psychoactive substance. A high percentage of adolescents from developed, as well as from underdeveloped countries, use it. Through the European Monitoring Centre for Drugs and Drug Addiction (EMCDDA) and the Pompidou Group, established by the Council of Europe, 
separate research on marijuana usage has been conducted in the BH entities, the Federation of BH and Republika Srpska. However, no research was conducted before in the Brčko District, which is also part of BH. The previous research showed that marijuana is present among adolescents in $\mathrm{BH}$, but the frequency of smoking varies between the two entities.

\section{What this study adds}

During this research, which was conducted in accordance with the methodology previously applied in the BH entities, data about marijuana smoking among adolescents from the Brčko District were collected and processed. The results of this research complement the perception of marijuana smoking among the BH adolescents, so that a full insight into marijuana usage in the whole of $\mathrm{BH}$ can be obtained, while in the Brčko District it is possible to implement marijuana smoking prevention programs and periodically repeat the research in order to monitor marijuana smoking trends.

Authors' contributions: Conception and design: AD, HT and MCS; Acquisition, analysis and interpretation of data: AD, HT and MCS; Drafting the article: AD; Revising it critically for important intellectual content: $\mathrm{AD}, \mathrm{HT}, \mathrm{MCS}$ and $\mathrm{BĐ}$; Approved final version of the manuscript: $\mathrm{AD}, \mathrm{HT}, \mathrm{MCS}$ and $\mathrm{BĐ}$.

Conflict of interest: The authors declare that they have no conflict of interest.

\section{References}

1. United Nations Office on Drugs and Crime (UNODC). World Drug Report 2012. (United Nations publication, Sales No E 12.XI.1). New York: United Nations; 2012 [cited 2017 May 3]. Available from: https://www.unodc.org/documents/ data-and-analysis/WDR2012/WDR_2012_web_ small.pdf.

2. Walker D, Neighbors C, Rodriguez L, Stephens R, Roffman R. Social norms and Self-efficacy Among Heavy Using Adolescent Marijuana Smokers. Psychol Addict Behav. 2011;25(4):727-32.

3. Pacek RL, Vandrey R. Cannabis Use History and Characteristics of Quit Attempts: A Comparison Study of Treatment - Seeking and Non-Treatment Seeking Cannabis Users. Exp Clin Psychopharmacol. 2014;22(6):517-23.

4. Hasin D, Keyes K, Alderson D, Wang S, Aharonovich E, Grant B. Cannabis withdrawal in the United States: a general population study. J Clin Psychiatry. 2008;69(9):1354-63.

5. World Health Organization (WHO). The health and social effects of nonmedical cannabis use. Geneva: WHO; 2016 [cited 2017 May 3]. Available from: http://www.who.int/substance_abuse/publications/msbcannabis.pdf.

6. Single Convention on Narcotic Drugs, 1961: As amended by the 1972 Protocol amending the Single Convention on Narcotic Drugs, 1961. Geneva: United Nations; 1972 [cited 2017 May 3]. Available from: https://www.unodc.org/pdf/convention_1961_en.pdf.

7. United Nations Office on Drugs and Crime (UNODOC). World Drug Report 2007. (United Nations Publication, Sales No. E. 07.XI.5) Vienna: United Nations; 2007 [cited 2017 May 3]. Available from: https://www.unodc.org/pdf/research/ wdr07/WDR_2007.pdf.

8. Volkow ND, Baler RD, Compton WM, Weiss SR. Adverse health effects of marijuana use. $\mathrm{N}$ Engl J Med. 2014;370(23):2219-27.

9. Mehmedic Z, Chandra S, Slade D, Denham H, Foster S, Patel AS, et al. Potency trends of $\triangle 9$-THC and other cannabinoids in confiscated cannabis preparations from 1993 to 2008. J Forensic Sci. 2010;55(5):1209-17.

10. Greydanus ED, Hawver KE, Greydanus MM, Merrick J. Marijuana: Current Concepts. Front Public Health. 2013;1:42.

11. Age limits and adolescents. Paediatr Child Health. 2003;8(9):577.

12. World Health Organization (WHO). Programming for adolescent health and development: report of a WHO/UNFPA/UNICEF Study Group on Programming for Adolescent Health. Geneva: World Health Organization; 1999 [cited 2017 May 3]. Available from: www.who.int/iris/handle/10665/42149.

13. Kipping RR, Campbell RM, Mac Arthur GJ, Gunnell DJ, Hickman M. Multiple risk and behavior in adolescence. J Public Health. 2012; 34(1):11-2.

14. Patton R, Cunningham RM, Carter PM, Walton AM. Comparing Substance Use and Violence Among Adolescents Recruited From an Urban Emergency Department: Does Parenting Status Matter? J Alcohol Drug Depend. 2015;3:3.

15. Fergusson DM, Boden JM, Horwood LJ. Cannabis use and other illicit drug use: testing the cannabis gateway hypothesis. Addiction. 2006;101(4):55669.

16. Budney AJ, Roffman R, Stephens RS, Walker D. Marijuana dependence and its treatment. Addict Sci Clin Pract. 2007;4(1):4-16.

17. Tu WA. Ratner AP, Johnson LJ Gender Differences in the Correlates of Adolescents Cannabis Use. Subst Use Misuse. 2008;43(10):1438-63.

18. Pinchevsky MG, Arria MA, Caldeira MK, Garnier-Dykstra ML, Vincent BK, O’Grady EK. Mari- 
juana Exposure Opportunity and Initiation during College: Parent and Peer Influences. Prev Sci. 2012;13(1):43-54.

19. King AK, Vidourek AR, Hoffman RA. Sex and grade level differences in marijuana use among youth. J Drug Education. 2012;42(3):361-77.

20. Tucker SJ, De la Haye K, Kennedy PD, Green DH, Pollard SM. Peer Influence on Marijuana Use in Different Types of Friendships. J Adolesc Health. 2014;54(1):67-73.

21. Shannon ML, Havens RJ, Oser C, Crosby R, Carl L. Examining gender differences in substance use and age of first use among rural, Appalachian drug users in Kentucky. Am J Drug Alcohol Abuse. 2011;37(2):98-104.

22. Martino SC, Ellickson PL, McCaffrey DF. Developmental trajectories of substance use from early to late adolescence: a comparison of rural and urban youth. J Stud Alcohol Drugs. 2008 May;69(3):430-40.

23. Scheer SD, Borden LM, Donnermeyer JF. The relationship between family factors and adolescent substance use in rural, suburban, and urban settings. J Child Fam Stud. 2000;2(1):105-15.

24. World Health Organization (WHO) [homepage on the internet]. WHO; 2017. Management of substance abuse [cited 2017 May 3]. Available from: http://www.who.int/substance_abuse/facts/ cannabis/en/.

25. Hibell B, Guttormsson U. A supplement to the 2011 ESPAD Report. Additional data from Bosnia and Herzegovina (Federation of Bosnia and Herzegovina), Kosovo (under UNSCR 1244) and the Netherlands. Stockholm: The Swedish Council for Information on Alcohol and Other Drugs; 2013.

26. Palamar JJ, Ompad DC, Petkova E. Correlates of intentions to use cannabis among US high school seniors in the case of cannabis legalization. Int J Drug Policy. 2014 May;25(3):424-35.
27. Agency for Statistics of $\mathrm{BiH}$. Demography in Brčko Distrikt of BH. Official register. 2012;(5):25.

28. Wikipedia. Bosnia and Herzegovina [cited 2017 May 3]. Available from: https://en.wikipedia.org/ wiki/Bosnia_and_Herzegovina.

29. Dijkstra L, Poelman H. Regional Working Paper 2014. A harmonised definition of cities and rural areas: the new degree of urbanisation. European Comission Directorate-General for Regional and Urban Policy: Working Paper; 2014.

30. Schepis TS, Desai RA, Cavallo DA, Smith AE, McFetridge A, Liss TB, Krishnan-Sarin S. Gender differences in adolescent marijuana use and associated psychosocial characteristics. J Addict Med. 2011;5(1):65-73.

31. Pejnović Franelić I, Kuzman M, Pavić Šimetin I, Kern J. Impact of environmental factors on marijuana use in 11 European countries. CMJ 2011;52(4):446-57.

32. Fattore L, Fratta W. How important are sex differences in cannabinoid action. Br J Pharmacol. 2010;160(3):544-8.

33. Hemovich V, Crano WD. Family structure and adolescent drug use: an exploration of single-parent families. Subst Use Misuse. 2009;44(14):2099-113.

34. Shakya BH, Christakis AN, Fowler HJ. Parental Influence on Substance Use in Adolescent Social Networks. Arch Pediatr Adolesc Med. 2012;166(12):1132-139.

35. Shannon ML, Havens RJ, Oser C, Crosby R, Leukefeld C. Examining gender differences in substance use and age of first use among rural, Appalachian drug users in Kentucky. Am J Drug Alcohol Abuse. 2011;37(2):98-104.

36. Anderson KG, Sitney M, White HR. Marijuana motivations across adolescence: impacts on use and consequences. Subst Use Misuse. 2015;50(3):292-301. 